\title{
Experiência estética como forma de internalização das relações de poder
}

\author{
Renata Santos de Morales* \\ Juliana Figueiró Ramiro** \\ Noeli Reck Maggi****
}

\section{Resumo}

O presente artigo, a partir do cruzamento das pesquisas de Lev Vygotsky, estudioso dos processos de aprendizagem, e de Michel Foucault, estudioso das relações de poder, traz para reflexão princípios teóricos acerca da educação estética e da internalização das experiências vividas como formas de absorção das relações de poder. Para isso, apresenta como objeto de análise a adaptação para crianças de um clássico da literatura internacional - Romeu e Julieta, de William Shakespeare -, feita pela autora brasileira Ruth Rocha (2009). Na obra adaptada, entendendo a sua leitura como experiência estética de alteridade, vamos observar de que forma questões de gênero (homem e mulher) são orquestradas na nova narrativa, buscando identificar as relações entre a experiência estética e possíveis conceitos morais imbricados na obra.

Palavras-chave: Discurso. Experiência estética. Gênero. Leitura. Poder.

* Mestra em Letras pelo Centro Universitário Ritter dos Reis e doutoranda em Letras na mesma instituição. Professora convidada da especialização em produção e revisão textual da Uniritter/Fapa. Pesquisa interações entre literatura e alteridade no contexto pós-colonial. É membro do Grupo Interdisciplinar de Pesquisa em Educação, Cultura e Sociedade do Conselho Nacional de Desenvolvimento Científico e Tecnológico (CNPq) e do laboratório de Ensino-Aprendizagem do PPG-Letras do Centro Universitário Ritter dos Reis. E-mail: renatasmorales@gmail.com

** Mestra em Design pelo Centro Universitário Ritter dos Reis e doutoranda em Letras na mesma instituição. Professora convidada da especialização em produção e revisão textual da Uniritter/Fapa. Pesquisa de forma interdisciplinar gênero, discurso e relações de poder. É membro do Grupo Interdisciplinar de Pesquisa em Educação, Cultura e Sociedade do Conselho Nacional de Desenvolvimento Científico e Tecnológico $(\mathrm{CNPq})$ e do laboratório de Ensino-Aprendizagem do PPG-Letras do Centro Universitário Ritter dos Reis. E-mail: admin@ julianaramiro.com.br

**** Doutora em Educação pela Universidade Federal do Rio Grande do Sul. Tem formação Psicanalítica pelo Círculo Psicanalítico do Rio Grande do Sul. Professora titular do Centro Universitário Ritter dos Reis, onde desempenha atividades de ensino e pesquisa na graduação e na pós-graduação em Educação e Letras. É membro do Comitê de Ética e Líder do Grupo Interdisciplinar de Pesquisa em Educação Cultura e Sociedade do Conselho Nacional de Desenvolvimento Científico e Tecnológico (CNPq). E-mail: nrmaggi@uniritter.edu.br

Data de submissão: 30/07/2017 - Data de aceite: ago. 2017 http://dx.doi.org/10.5335/rdes.v13i2.7271 


\section{Introdução}

A construção do conhecimento e a atribuição de significados e sentidos para os fenômenos do mundo, em uma perspectiva sociointeracionista, podem processar-se pela internalização de experiências externas, facilitada pela mediação social, que pode fazer uso de dispositivos materiais e psicológicos representados por instrumentos, signos e símbolos.

Neste sentido, Vigotsky (2010) destaca a linguagem como um desses instrumentos e também como função psicológica superior, constituída pela influência direta dos movimentos históricos e culturais. Essa visão teórica nos alerta para a necessidade de estudar sistematicamente as formas como o sujeito recebe e percebe esses movimentos e como os modos de mediação ou ferramentas culturais estão envolvidos nesse processo. A mediação é feita por sujeitos, portadores de uma história social e cultural que traduz determinados conceitos, valores e imagem de mundo.

Em situação de aprendizagem escolar, por exemplo, a mediação pode ser aplicada a partir da relação entre pares com níveis de competências diferentes, para possibilitar o crescimento cognitivo e a experiência da relação de alteridade, oportunizando aos sujeitos novas formas de significar e dar sentido ao mundo, como também pode advir de vivências poéticas ou estéticas, por exemplo, a partir da leitura. É nesta segunda pos- sibilidade de mediação descrita, que acontece via leitura, que está o foco de interesse deste artigo.

Segundo Vigotsky,

[...] toda vivência poética [assim como a estética] parece acumular energia para futuras ações, dá a essas ações um novo sentido e leva a ver o mundo com novos olhos (2010, p. 343).

O mesmo autor que, com tal afirmação, vislumbra na vivência poética um espaço do novo e da ressignificação do mundo, é quem nos alerta sobre aquela que ele chamou de "falsa literatura infantil".

Vygotsky, em seus estudos sobre a educação estética, na obra Psicologia Pedagógica (2010), diz que, muitas vezes, a educação formal se utiliza da educação estética, seja ela imagética ou literária, para construir valores morais nas crianças. Segundo o autor:

Organizam-se as bibliotecas infantis com a finalidade de que as crianças tirem dos livros exemplos morais ilustrativos e lições edificantes, a enfadonha moral da rotina e os sermões falsamente edificantes se tornaram uma espécie de estilo obrigatório de uma falsa literatura infantil (VYGOTSKY, 2010, p. 324).

A partir do que o autor coloca nesse estudo, buscamos identificar as relações entre a experiência estética da leitura e possíveis conceitos morais imbricados nela, tendo como objeto de estudo a adaptação para crianças de um clássico da literatura internacional de William Shakespeare - Romeu e Julieta -, feita pela autora brasileira Ruth Rocha. Nosso objetivo também é observar o ato 
de leitura como experiência a partir da qual o sujeito significa os fenômenos do mundo, isto é, vai construindo verdades, que nutrem as relações de poder, aqui observadas a partir dos estudos do filósofo francês Michael Foucault, com o recorte central nas questões de gênero.

A leitura, no contexto apresentado neste estudo, é tomada como experiência estética e de prática da alteridade, em que o sujeito encontra modelos e experiências que poderão ser internalizados e que, por isso, darão sentido e significado às vivências do leitor. Ao ler, o sujeito estabelece contato com o outro em um movimento de aproximação e distanciamento. Ele sente que faz parte do texto que está lendo, encontrando aspectos que o tocam profundamente. Em outras palavras, a literatura afeta o indivíduo "quando mostra uma alteridade que ecoa de forma desconhecida ou até misteriosa" (SCHWAB, 1996, p. 10).

Partiremos de preceitos teóricos apoiados nas perspectivas de Vigotsky e de Foucault, para refletirmos acerca da leitura em sua dimensão estética e da internalização das experiências como forma de absorção de conceitos morais e de questões de gênero. Assim, na obra adaptada, vamos observar de que forma os discursos são orquestrados na nova narrativa, gerando sentido.

\section{Vigotsky e Foucault: experiência estética e relações de poder}

No livro Psicologia pedagógica, Vygotsky (2010) destaca os três equívocos cometidos pela pedagogia tradicional com relação à educação estética. Para ele, existe um engano quando a escola se utiliza de objetos estéticos, como um livro, um desenho, uma história, para ensinar uma determinada moral - ato exemplificado por ele na sua crítica com relação às bibliotecas infantis, citada anteriormente neste estudo.

O segundo desacerto da pedagogia é, mais uma vez, deixar o estudo estético de lado e debruçar-se nos elementos sociais contidos em determinada obra. Por fim, o terceiro erro, de acordo com o autor, é ter a estética apenas como fonte que suscita prazer e alegria na criança, subestimando a psicologia infantil. Sobre tal subestimação, Vygotsky, ao tratar sobre contos de fada, ainda traz um outro lado:

[...] profundo desrespeito pela realidade e a preponderância do invisível que esse tipo de conto sistematicamente educa. A criança fica tola e obtusa diante do mundo real, fecha-se em um clima doentio e doloroso, o mais das vezes em um reino de invencionices fantásticas (2010, p. 355).

No estudo que aqui propomos, nossa intenção é, a partir da observação de um objeto concreto, ponderar esses aspectos não como meros equívocos, mas como discursos construídos que são permeados por significados e sentidos que constroem 
e/ou reafirmam relações de poder. Vygotsky não se dedicou a estudar as relações de poder, mas, em muitos trechos da sua pesquisa, tais conexões estão postas. Para o autor,

[...] no psiquismo, como no mundo, nada passa sem deixar vestígios, nada desaparece, tudo cria os seus hábitos que acabam permanecendo para o resto da vida (2010, p. 348).

Quando Vygotsky fala da validação dos hábitos e dos vestígios deixados em nós daquilo que consumimos, podemos aproximá-lo dos estudos de Foucault sobre o poder. Em A História da Sexualidade (2012), Foucault define o poder como o nome que se atribui a uma situação complexa dentro de um contexto definido em uma sociedade (FOUCAULT, 2012, p. 93). As relações estratégicas de poder acontecem pela via do discurso que é, para o autor, a forma pela qual o conhecimento se constrói, juntamente com as práticas sociais. Poder - via discurso - e conhecimento se constituem mutuamente e são mais do que apenas formas de pensamento, pois se relacionam e, assim, deixam vestígios no corpo, no consciente e no inconsciente dos sujeitos.

O centro da teoria sociointeracionista, na qual Vygotsky ancorou seus estudos, fala justamente da constituição do sujeito a partir do ambiente externo, isto é, a partir do discurso do outro. Dedicado a estudar as crianças e sua psiquê, com o recorte na educação, o autor aponta o fato de que, sendo as crianças verdadeiras "esponjas" - quando da absorção do mundo externo, a partir do emprego do conceito de plasticidade cerebral -, se nessa época forem forçadas a regular e orientar a sua existência a partir de uma dada moral e de concepções notoriamente equivocadas, é certo que tais estímulos deixarão vestígios no agir desses sujeitos.

Foucault diz que um discurso é composto por um "conjunto de regras anônimas, históricas, sempre determinadas no tempo e no espaço, que definiram uma determinada época" (2009, p. 153), e objetiva construir verdades, quando se afirma enquanto tal e denuncia inverdades construídas ao seu redor.

Nesse sentido, considerando, ainda, o que nos traz Vygotsky sobre os estímulos, podemos criticamente pensar que, se oferecermos os mesmos discursos a longo prazo, teremos os mesmos vestígios permeando a existência de novos sujeitos e, assim, fazendo um paralelo com a teoria foucaultiana, mais uma vez, veremos as mesmas verdades circulando no ambiente sócio-histórico e cultural. Com um agravante: dissimuladas de literatura infantil.

Sabemos que todo discurso, segundo Foucault (2001), visa ao poder e à dominação e também que, de acordo com Vygotsky (2010), um certo efeito moral é inerente à arte. Isso é o que sabemos. Porém, nossa inquietude nos faz buscar mais, tentando responder as seguintes questões: que moral é apresentada para as crianças? A partir de que verdades? $\mathrm{O}$ que está na literatura infantil serve para ressignificar o mundo ou alimentá-lo das 
mesmas verdades? Nosso recorte está fixado nas questões de gênero.

\section{Questões de gênero e o atual ambiente socio- histórico e cultural brasileiro}

Entre as diversas questões sociais que continuam a desafiar as políticas de desenvolvimento no Brasil, estão as questões de gênero. Não só é dada pouca atenção a elas, como também delas deriva uma multiplicidade de outras questões que atingem um número significativo de sujeitos, incluindo crianças e adolescentes, que estão inseridos em realidades cada vez mais complexas e com problemas sociais conjunturais.

A desigualdade oriunda das questões de gênero que acometem as mulheres de todas as idades é percebida, ou talvez passe a ser despercebida, em ações cotidianas, quando a mulher é socialmente responsável por cuidar dos filhos, limpar a casa e obedecer ao marido, passando pelo mercado de trabalho, em que elas, com a mesma formação, ou até com formação superior que os homens, ocupando os mesmos cargos, são retribuídas com salários inferiores, chegando a casos mais graves, em que são vítimas de variados tipos de violência.

Segundo dados do Instituto Brasileiro de Geografia e Estatística (IBGE, 2015), no mercado de trabalho brasileiro, homens ganham mais do que mulheres em todas as faixas etárias, em diferentes níveis de instrução, cargos e tipos de negócios e empresas. Madalozzo, Martins e Shiratori (2010) analisaram esses dados e concluíram que, estatisticamente, homens e mulheres no Brasil trabalham durante o ano todo, porém, as mulheres, se recebessem salário igual ao dos homens, ocupando os mesmos cargos, só teriam remuneração até 19 de outubro. Dessa data em diante, eles seguiriam recebendo salário normalmente e elas trabalhariam de graça, devido à diferença salarial entre os gêneros.

Nos espaços políticos e de poder, os salários são equivalentes, porém as mulheres estão sub-representadas. De acordo com levantamento realizado pelo IBGE, em 2015, as mulheres formavam $50,6 \%$ da população brasileira. Seguindo a lógica de que senadores, deputados federais e estaduais, prefeitos e vereadores são representantes do povo nos espaços de poder, faz-se lógico pensar que as mulheres deveriam ocupar pouco mais de $50 \%$ dos cargos para que houvesse real representatividade. A realidade é outra. Na Câmara dos Deputados, em 2015, a proporção ficou em uma mulher para cada dez deputados homens eleitos. $\mathrm{Na}$ Assembleia Legislativa do Rio Grande do Sul, para citar outro exemplo, dos 55 deputados eleitos em 2014, somente nove são mulheres. No Senado Federal a situação não é diferente, das 81 vagas, apenas 11 são ocupadas por mulheres. Que outro argumento pode ser posto para explicar a evidente desvantagem, 
em diferentes esferas, em que a mulher se encontra na sociedade brasileira, se não a desigualdade de gênero?

Se observarmos a desigualdade de gênero como um discurso da sociedade brasileira e entendermos, retomando Foucault (2001), que todo discurso visa ao poder e à dominação, a situação da mulher que resumidamente expusemos anteriormente pode ser entendida como um discurso que visa a reafirmar a supremacia do eu-homem em relação ao outro-mulher. Simone de Beauvoir, no volume I (2016) da sua obra sobre o segundo sexo, denuncia tal relação, que exacerba e valida a violência para com o sujeito dominado, a mulher.

Em 2015, segundo dados da Secretaria de Políticas para as Mulheres da Presidência da República (SPM-PR) (BRASIL, 2015), o Brasil registrou, de janeiro a outubro, mais de 63 mil denúncias de violência contra a mulher, isso significa que, diariamente, a cada sete minutos, uma mulher denunciou um caso de agressão. É importante ressaltar que esses são apenas números de casos delatados, ficando de fora todos aqueles episódios em que as mulheres sofrem caladas. Entre as situações relatadas, em mais de $80 \%$ delas, as agressões foram praticadas por homens com os quais as vítimas mantinham algum vínculo afetivo. Outro fato que faz com que o Brasil esteja na quinta posição, no ranking dos 20 países mais violentos para as mulheres, ficando atrás apenas de Rússia, Guatemala, Colômbia e El Salvador, é o de que, a partir de levantamento feito em 2014, aqui, uma mulher é estuprada a cada 11 minutos.

Se considerarmos os dados de violência contra a mulher no Brasil sob esse viés, mais uma vez fica evidente que existe uma relação de poder entre os gêneros, em que a mulher é o sujeito oprimido. Tal dinâmica é a base do machismo presente na sociedade brasileira, que reafirma e discursa a desigualdade entre os gêneros, e que nem sempre agride fisicamente as mulheres, mas as diminui, estigmatiza-as, esteriotipifica-as, condiciona-as e ainda faz com que reproduzam suas próprias condições, condenando mulheres que buscam romper com suas amarras, educando seus filhos a alimentarem seu próprio aprisionamento.

\section{Tornar-se homem e mulher: um discurso}

Simone de Beauvoir, na sua obra $O$ Segundo Sexo (2016b), traz uma das frases mais utilizadas pelos movimentos feministas ao redor do mundo para discutir a mulher: "Ninguém nasce mulher: torna-se mulher". Beauvoir, com esse enunciado, aponta que nenhum "destino" biológico, psíquico e econômico é responsável por definir a forma como a fêmea humana se apresenta na sociedade. É a própria sociedade que desenvolve o que ela chamou de "produto intermediário entre o macho e o castrado que qualificam o feminino" (BEAUVOIR, 2016b, p. 11). 
Quando uma criança nasce e existe apenas para si, sem se observar na relação com o outro, ela não se vê sexualmente diferenciada. O corpo, para meninos e meninas, segundo Beauvoir (2016b), é o instrumento que utilizam para compreender o mundo. Os bebês utilizam os olhos e as mãos para absorver o que os cerca. Suas partes genitais não tem papel nesse processo. Ambos descobrem o prazer da alimentação, via sucção, e, na fase anal, a satisfação de exercitar suas funções excretórias. Assim, o perceber-se e o consolidar-se homem e mulher se dão no contato e na apreensão do ser com e do ambiente que o envolve.

Eliot (2013) explica as diferenças entre os sexos nos seus estudos a partir do conceito de plasticidade cerebral, também apontado por Vygotsky (2010), que diz da capacidade do cérebro de responder às suas experiências. Para a autora, a plasticidade é a base de toda a aprendizagem, e é na infância que o cérebro é mais maleável e facilmente se molda a partir das experiências em que é submetido. A plasticidade, para a autora, significa que o cérebro é o que o usuário faz com ele, isto é, a que tarefas ele é apresentado.

Segundo Eliot (2013), aprender e praticar criam redes neurais no cérebro, e, se forem consideradas as maneiras distintas como meninas e meninos são estimulados a passar o tempo, é lógico que, na idade adulta, eles terão conexões cerebrais distintas. De acordo com a autora, entretanto, as diferenças homem-mulher que têm maior impacto - fala, leitura, capacidade matemática e mecânica, habilidades cognitivas e interpessoais - são profundamente moldadas pela aprendizagem.

Assim, podemos afirmar que meninos e meninas são treinados através da materialidade cotidiana de um discurso totalizante que diferencia os sujeitos pelo seu gênero, para serem efetivamente aceitos socialmente. Biólogos chamam a relação sujeito e meio de epigenética, que é quando o ambiente atua sobre ou através dos genes, criando os atributos humanos.

Nos seus estudos, Eliot (2013) apresenta atributos opostos que foram impostos e validados socialmente para cada um dos gêneros. Ao masculino, cabe ser corajoso, agressivo, impulsivo, racional, forte, realista e possuidor de habilidades físicas; ao feminino, cabe ser medroso, delicado, calmo, passional, frágil, adepto aos sonhos e habilidoso na sua motricidade fina apurada. Mesmo com pouquíssima validação física e genética para tal, esse modelo segue reproduzido e estimulado na sociedade brasileira. E dele surgem os preconceitos, os dogmas e a validação das relações entre homens e mulheres marcadas pela dominação, a submissão e a violência.

A reprodução de discursos que versam sobre como deve ser o sujeito-homem e o sujeito-mulher acontece no cotidiano, nos espaços de poder, nas instituições públicas e privadas, na publicidade, na educação diária e nas instituições de en- 
sino, como discorreu-se até aqui. Um fato novo, para citar um exemplo que dialoga com as questões de gênero, é a retirada de dois temas do Plano Nacional de Educação (PNE) no ano de 2015 (CANCIAN, 2017). A ação foi reproduzida também nos planos estaduais e municipais. Os temas são: identidade de gênero e sexualidade. O principal argumento para tal movimento, amplamente divulgado na mídia, foi o de que trazer esses conceitos à tona deturparia os conceitos de homem e mulher. Isto é, existem conceitos praticados e estimulados na educação. $\mathrm{E}$, na literatura infantil, temos estética ou moral sendo trabalhada com as crianças? Como isso se dá?

\section{Leitura como experiência estética de alteridade}

Gabriele Schwab, em sua obra The Mirror and The Killer-Queen (1996), sugere um olhar para a função cultural das práticas estéticas, questão que trabalha em relação à alteridade numa abordagem antropológica. Para ela, a alteridade surge como consequência do ato de leitura, que se coloca como forma de contato cultural.

A partir de um estudo conduzido pela antropóloga Laura Bohannan, no qual a universalidade dos temas presentes nas obras de Shakespeare foi posta à prova, Schwab (1996) trata dos múltiplos efeitos da leitura sob a ótica da alteridade cultural. Segundo ela, nunca o sujeito está exposto meramente aos fatos de um encontro cultural, mas às suas múltiplas refrações em narrativas que refletem relações formadas por expectativas específicas, preconceitos, desejos, necessidades e medos projetados no outro.

$\mathrm{O}$ ato da leitura, concebido enquanto prática da alteridade e de contato cultural, deve ser visto como um exercício de negociação com o outro. Haveria, portanto, uma negociação entre culturas e fronteiras históricas. Sob essa ótica, ao ler, o leitor se encontra em uma avenida de mão dupla - de um lado, temos a cultura presente no texto e, de outro, o âmbito cultural em que está inserido o sujeito.

Além disso, é importante considerarmos a opinião de Schwab (1996) no que diz respeito à questão da interpretação e do mecanismo exercido pelo leitor. Segundo a autora, é preciso ter em mente que existem normas internalizadas, a que se recorre ao interpretar uma narrativa, que estão diretamente ligadas ao contexto cultural. Assim, no ato da leitura, exerce-se uma conexão entre a realidade cultural do sujeito e a do texto. Esse processo, destaca a autora, passa quase desapercebido, pois o leitor pouco percebe - se é que chega a perceber que é necessário que ele percorra tal caminho de negociação. A exceção, coloca Schwab (1996), se dá quando o sujeito se depara com um texto extremamente estrangeiro, uma prática estética radicalmente inovadora ou uma interpretação contundentemente diferente, marcando definitivamente a leitura como forma de contato cultural. 
No ato de ler, o sujeito busca observar o outro dentro da cultura dele, o que é constatado nesse exercício: o sujeito transpõe para a sua cultura e para si mesmo. Assim, uma das formas de entender ou avaliar o papel de uma obra literária enquanto exercício de alteridade se dá através da observação da distância cultural entre o leitor e o texto. $\mathrm{O}$ dar-se conta dessa distância seria um primeiro passo para entender a importância da intervenção cultural.

Além disso, não se pode ficar unicamente no campo da análise semântica ou temática de uma obra. Para compreender a importância do contato cultural, é necessário que a função estética e a forma do modo de apresentação e recepção da obra sejam levadas em conta (SCHWAB, 1996).

Neste sentido, de acordo com a proposta de Schwab (1996), é fundamental que a ênfase das teorias literárias seja voltada para a experiência de negociação cultural, vendo a leitura como instrumento que afeta as fronteiras culturais, tanto individuais como de uma comunidade, de forma que tais fronteiras mudem, atualizem-se, desfaçam-se e refaçam-se novamente.

A partir dos apontamentos de Schwab (1996), em nossos momentos de análise, vamos observar nosso objeto de estudo inserido nas relações de poder, com o recorte de gênero, mas também sua leitura como contato cultural, buscando descrever os aspectos culturais presentes na obra. Ainda, cabe destacar que enten- demos que o público-alvo da literatura infantil é a criança, porém reconhecemos que ela já carrega em si traços da sua cultura e, num ato de leitura, percorre o caminho da alteridade. Não queremos aqui cair em outro erro destacado por Vygotsky (2010) - o de subestimar a psicologia infantil.

\section{Análise e discussão}

A obra original Romeu e Julieta, de Willian Shakespeare, passa-se em Verona, na Itália, por volta de 1500, e conta a história de amor de um casal de jovens (Romeu e Julieta), que, apesar de serem de famílias rivais - os Montéquio e os Capuleto -, se apaixonam um pelo outro. Suas famílias são inimigas há muitos anos.

Certo dia, o patriarca da família Capuleto, pai de Julieta, dá uma grande festa para a qual convida muitos amigos. Por óbvio, a família Montéquio não faz parte da lista dos convidados. Todavia, Romeu está interessado em Rosalina, uma das jovens que foi convidada para $o$ evento, e monta um plano para que possa participar da festa, para ficar mais perto de Rosalina. Romeu entra disfarçado na casa dos inimigos da sua família, onde conhece Julieta e fica encantado por ela. Apaixona-se de imediato pela jovem, que, de certa forma, retribui o interesse, não sabendo que ele pertence à família inimiga da sua.

Mais tarde, Julieta, depois de descobrir que o jovem por quem estava apai- 
xonada é o filho da família inimiga, vai para a varanda e conta às estrelas que tem um amor proibido. Romeu, escondido nos arbustos debaixo da varanda, ouve as confissões de Julieta e não resiste. Apresenta-se à moça e declara-se. Com a ajuda de um amigo - Frei Lourenço -, Romeu e Julieta se casam em segredo, no dia seguinte.

No dia do casamento, dois amigos de Romeu, Benvólio e Mercúcio, passeiam pelas ruas de Verona e encontram-se com Teobaldo, primo de Julieta. Teobaldo, que ficara sabendo que Romeu tinha se feito presente na casa de seus tios, procura por ele para se vingar. No encontro com Benvólio e Mercúcio, Teobaldo acaba discutindo com os amigos de Romeu. Romeu aparece e coloca-se no sentido de apaziguar a briga. Porém, seus amigos não percebem sua atitude de trégua, e Mercúcio resolve defender a honra do amigo, começando um duelo com Teobaldo, no qual acaba morto. Romeu vinga a morte do amigo vitimando Teobaldo com um golpe de espada.

O ocorrido faz com que Romeu seja ainda mais odiado pelos Capuletos. O príncipe de Verona expulsa Romeu da cidade, que não tem outra alternativa a não ser deixar Julieta, que sofre imensamente com a partida do amado. $O$ pai de Julieta, que não sabia do seu casamento com Romeu, resolve casá-la com um jovem chamado Páris.

Desesperada, Julieta pede ajuda a Frei Lourenço, que a aconselha a aceitar o casamento, sugerindo que, na manhã do evento, Julieta beba uma poção, que a fará parecer morta. Assim, ela é levada para o jazigo da família. Frei avisa Romeu para ir encontrar-se com ela. Julieta faz tudo o que o frei manda e é deixada no jazigo. Porém, antes que o frei pudesse avisar Romeu, ele ouve a notícia da morte de Julieta, compra um frasco de veneno, vai até o jazigo onde Julieta está e morre ao seu lado. Momentos depois, Julieta acorda e vê o corpo morto de Romeu. Frei Lourenço aparece e conta a Julieta o que se passou. Ela pega o punhal de Romeu e mata-se, pois já não vê motivos para seguir viva. A tragédia tem um grande impacto nas famílias Montéquio e Capuleto. Ambas ficam tão tocadas com a morte dos seus dois únicos descendentes, que decidem nunca mais lutar, fazendo as pazes.

$\mathrm{Na}$ adaptação infantil de Ruth Rocha, Romeu e Julieta são borboletas de cores diferentes. Romeu é azul e Julieta é amarela. Num paralelo com a obra original, as cores representam as famílias. $\mathrm{Na}$ adaptação, os pais da dupla destacam o fato de que as borboletas de uma cor não devem se misturar com as de outra, tampouco visitar flores de cores diferentes da sua. As flores, na obra, representam a casa das borboletas e fazem alusão ao encontro de Romeu e Julieta, na obra original, que aconteceu na casa dela.

Romeu, na adaptação, é o primeiro a romper com a regra estabelecida pelos pais e, junto com seu amigo Ventinho, sai para um passeio no qual encontra Julieta. Os três amigos se divertem 
muito juntos, livres, até que encontram uma família de humanos, que fazia um piquenique, numa clareira da floresta. $\mathrm{O}$ menino mais velho convida a irmã menor para caçar borboletas para a sua coleção, o que deixa Romeu e Julieta assustados, fazendo-os fugir. Na fuga, perdem-se na floresta e passam a noite sozinhos, no escuro, enquanto suas famílias procuram por eles. Todos juntos buscam por Julieta e Romeu e encontraram-nos. Após o susto, quando chega mais uma vez a primavera, todas os canteiros, que antes eram divididos por cor, passam a ter flores coloridas, e as borboletas se integram umas com as outras, numa alusão ao final do texto original de Romeu e Julieta, no qual, após a tragédia da morte do casal, as duas famílias rivais decidem viver em paz.

Numa perceptiva de alteridade, a obra oportuniza que a criança percorra, no mínimo, três caminhos. No primeiro deles, e talvez o mais óbvio, a criança se coloca no lugar do eu, isto é, percebe-se como Romeu e/ou Julieta, colocando-se no papel da criança que quer brincar, ser livre, e vê-se na obrigação de obedecer aos pais. No segundo caminho, assume o lugar do outro, neste caso, dos pais, entendendo a necessidade das regras para manter os filhos longe de perigos, a preocupação que os pais sentem quando os filhos não seguem tais regras e, por fim, o sofrimento que os filhos causam quando não fazem o que foi combinado. $\mathrm{E}$, numa terceira possibilidade de alteridade, a criança coloca-se no lugar do humano, também um outro, que brinca, diverte-se e coleciona coisas, mas que seus hábitos podem ameaçar a vida de outrem, dos amigos e do meio ambiente.

De modo geral, na obra adaptada, percebemos, para além das cores e do lúdico, isto é, para além do estético e da aproximação com a história original, a tentativa de construir valores morais para os leitores, como já denunciava Vygotsky (2010). A obediência às regras impostas pelos pais e o ambiente sócio-histórico e cultural que, de certa forma, os pais personificam são, sem dúvida, o traço moral mais evidente e de fácil percepção da adaptação de Ruth Rocha.

Se considerarmos a moral a partir do entendimento trazido pelo Dicionário Houaiss, de que ela é aquela "que denota bons costumes segundo os preceitos estabelecidos por um determinado grupo social” (2001, p. p. 650), outro traço moral não tão evidente, mas simbolicamente presente e construído na adaptação para crianças que se relaciona diretamente com o poder, tem a ver com as questões de gênero e os "bons costumes", isto é, as práticas socialmente reiteradas que devem ser exercidas por homens e mulheres, meninos e meninas, para serem aceitos e validados como tais. A partir da reafirmação de costumes, a adaptação de Romeu e Julieta, via moral, condiciona a existência dos sujeitos de ambos os sexos, dando elementos para as crianças para que se submetam.

A adaptação remonta àquilo que nosso ambiente historicamente estabeleceu 
como sendo papel e postura de um e de outro sexo. Julieta, a menina, é descrita no diminutivo - "engraçadinha" (ROCHA, 2009, p. 07) - e aparece em boa parte do texto ao lado da mãe, copiando seu comportamento. Quando a mãe dispara ordens com as quais ela não pactua, não subverte, apenas fica triste, "fecha as asas, abaixa as antenas e chora uma lágrima amarela de borboleta..." (2009, p. 09). Já Romeu, o menino-borboleta, representado pela cor azul, além de não ser descrito no diminutivo - Romeu não é engraçadinho e sim "engraçado" (2009, p. 11) -, tem suas habilidades motoras destacadas. Enquanto Julieta "já sabe voar" (2009, p. 07), Romeu "sabe voar para frente e para trás” (2009, p. 11), dá cambalhotas no ar, voa com uma asa só, borboleteia por todo lado e, quando é surpreendido pelas ordens do pai, sobre não passear em outros canteiros, argumenta com o pai e questiona-se "por quê?" (2009, p. 13).

Nos trechos destacados anteriormente, percebemos os discursos a serviço da moral e do poder, reafirmando a supremacia do homem. A ele, representado em Romeu, cabe questionar, argumentar, insurgir-se; já à mulher, contada a partir de Julieta, que historicamente sempre deveu obediência - ao pai, à mãe, ao marido -, cabe o assujeitamento.

Ainda, as habilidades de Romeu em comparação a Julieta também podem ser vistas inseridas numa perspectiva de poder e condicionamento do sujeito, visto que existe uma separação fortemente marcada entre as habilidades de um e de outro, isto é, do que é ser homem e do que é ser mulher, retomando Eliot (2013) sobre os atributos impostos e validados socialmente a cada um dos gêneros.

Na sequência da adaptação, Romeu é descrito como "muito curioso" (2009, p. 14), pois tinha o desejo de conhecer todas as cores, as flores e os canteiros, enquanto Julieta, no mesmo trecho, é descrita como "boazinha" (2009, p. 15). Ventinho, o amigo de Romeu, ainda afirma a ele: "duvido que ela não goste de você" (2009, p. 15), convidando Romeu a visitar o canteiro das margaridas, para encontrar Julieta. No trecho, percebem-se, mais uma vez, traços da personalidade construída e atribuída aos gêneros - Romeu é o homem curioso, que quer conhecer tudo, enquanto Julieta é construída de forma passiva, a mulher que espera a chegada do homem e que, por ser "boazinha", certamente irá gostar daquele que surgir.

$\mathrm{O}$ trecho pode ser relacionado com a servidão feminina, descrita em "Efésio", capítulo 5 (BÍBLIA, 1966), e em outros trechos da Bíblia - o principal livro que rege a moral judaico-cristã, que em muito influencia o ambiente sócio-histórico do sujeito consumidor do conteúdo do livro. Lá, assim é descrita a servidão:

As mulheres sejam submissas a seus maridos, como ao Senhor, pois o marido é o chefe da mulher, como Cristo é o chefe da Igreja, seu corpo, da qual ele é o Salvador. Ora, assim como a Igreja é submissa a Cristo, assim também o sejam em tudo as mulheres a seus maridos (BÍBLIA, Efésio, 5, 22-24). 
Seguindo na obra adaptada por Ruth Rocha, Romeu e Julieta se conhecem e ficam amigos logo de cara. O livro mostra Julieta sentada numa flor observando Romeu, que, conforme descrito, "[...] fez tudo o que sabia para Julieta ver" (2009, p. 18). Quando Julieta assume uma posição mais ativa e parte para uma cambalhota junto com Romeu, erra, pois nunca havia dado cambalhotas antes. Nisso, Romeu dá uma "risada" (2009, p. 19), enquanto Julieta, uma "risadinha" (2009, p. 19). Mais uma vez é possível observar a moral a serviço da construção dos estereótipos dos gêneros com um agravante: quando Julieta tenta romper com o papel que lhe cabe, arriscando-se em algo novo, tido como masculino, erra. Tal construção sugere uma espécie de punição para a mulher que sai do que foi estabelecido - ela vai errar e o eu-superior vai rir.

Quando Romeu e Julieta ficam perdidos na Floresta, as famílias de ambos entram em cena. $\mathrm{E}$ o reforço de gênero segue. Enquanto a mãe de Julieta chora e a mãe de Romeu grita - características historicamente atribuídas às mulheres, ditas "loucas e sensíveis" -, os pais procuram pelos filhos sem sinais de desespero e sem abandonar seus canteiros, isto é, sem romper com a regra de não misturarem as famílias que, num sistema patriarcal, são representadas pelo nome do pai. Assim, podemos observar a atitude dos pais como um gesto de resguardar o próprio nome antes de mais nada.
Nas cenas em que se descrevem Romeu e Julieta perdidos na floresta, Romeu está introspectivo, sem falas, enquanto Julieta lamenta estarem perdidos num tom derrotado: "não adianta, Romeu, nós não sabemos o caminho..." (2009, p. 28). Ainda, Julieta é descrita como a que sente as intempéries da floresta: "Julieta tremia de frio" (2009, p. 29). Esse fato pode ser relacionado com a dita sensibilidade do amplamente citado "sexo frágil". Romeu não sente frio, Julieta sim.

Nos trechos seguintes da obra adaptada, quando as famílias encontram os filhos, as mulheres protagonizam as cenas. Uma margarida fala com a mãe de Julieta sobre a filha dela, conta sobre Romeu e Ventinho terem saído juntos para a Floresta, a mãe de Julieta "cria coragem" (2009, p. 31) e vai falar com a mãe de Romeu, juntas elas chamam os maridos para irem atrás dos filhos. O trecho pode ser observado como um momento de protagonismo das mulheres, mas também, se observadas as vezes em que o termo "falar" e variações é utilizado -5 vezes no total -, podemos dizer que, de alguma forma, a repetição serve para apontar para uma característica feminina construída e vista com certo desdém: falar demais. As mulheres falam, falam, falam, todavia, só vão em busca dos filhos após chamarem os maridos.

No desfecho da história, quando as famílias encontram os filhos, mais uma vez, existe um reforço dos papéis de cada gênero. "E cada mamãe pegou $o$ 
seu filhinho" (2009, p. 35), enquanto os pais observam a cena, pois se envolvem menos com o trato dos filhos. Algo que é amplamente reproduzido nas famílias e no próprio mercado de trabalho, como vimos, que não valoriza as mulheres com igualdade, pois, no fundo, elas não deveriam estar ali, mas em casa, cuidando dos filhos.

\section{Considerações finais}

A partir do que nos traz Schwab (1996), sobre a leitura oportunizar o contato cultural, nestas breves considerações finais, cabe a nós destacarmos que, no objeto a que nos propusemos observar, é possível perceber o que está subjacente na adaptação de Ruth Rocha. Mesmo que na adaptação infantil prevaleça o lúdico, e por ter tal característica, teria espaço para romper com a cultura na qual o leitor está inserido, o livro, no entanto, não o faz. O que percebemos é o espelhamento da cultura do leitor na obra. Esse movimento pode ser observado como uma espécie de reforço cultural e moral, que reafirma a supremacia do eu-homem na relação ao outro-mulher, $\mathrm{e}$ ampara os "bons costumes" e as características que devem orientar a existência de ambos os sexos.

Outro fato que merece ser destacado é a existência da moral, como havia denunciado Vygotsky (2010), forjada de educação estética. Essa Moral se coloca a serviço de verdades e discursos totali- zantes de poder com relação aos gêneros dos sujeitos.

Por fim, vemos ser significativo destacar um aspecto que valida o exercício analítico aqui desenvolvido e também faz dele um alerta. Assim, ressaltamos o fato de que as relações de poder que permeiam as questões de gênero se manifestam nos mais diversos âmbitos e, para as crianças, ficam provadas também pela via da literatura infantil, de forma lúdica, forjada de leve e desinteressada moralmente, porém propagando sentidos que vão muito além da primeira camada de percepção da experiência estética, como apontou Vygotsky (2010). Neste sentido, enfatizamos a necessidade de reflexão, questionamento e senso de responsabilidade por parte dos educadores ao selecionarem materiais de mediação a serem usados em sala de aula, devendo levar em consideração aspectos que ultrapassem as questões meramente linguísticas. Para nós, também esse é papel do professor enquanto sujeito - principalmente a partir do entendimento de que não existe sujeito-isento: contribuir para o mundo em que vive e/ ou gostaria de viver. 


\section{Aesthetic Experience as a form of internalization of power relations}

\begin{abstract}
The present article, based on the research of Lev Vygotsky, a researcher of learning processes, and Michel Foucault, a researcher of power relations, seeks to reflect theoretical principles related to aesthetic education and internalization of experiences as a form of absorption of power. In order to do so, the study analyzes the adaptation for children of a classic story of the international literature, William Shakespeare's Romeo and Juliet, adapted by the Brazilian writer Ruth Rocha. In the adapted book, considering its reading as an aesthetical experience of otherness, we aim at observing how gender issues (man and woman) are orchestrated in the new narrative, seeking to identify the relations between aesthetic experience and possible moral concepts imbricated in it.
\end{abstract}

Keywords: Aesthetic experience. Discourse. Gender. Power. Reading.

\section{Referências}

BEAUVOIR, Simone de. O segundo sexo: experiência vivida. 3. ed. Rio de Janeiro: Nova Fronteira, 2016a.

. O segundo sexo: fatos e mitos. 3. ed. Rio de Janeiro: Nova Fronteira, 2016b.

BÍBLIA. A. T. Efésio. In: BÍBLIA. Português. Bíblia sagrada: contendo o antigo e o novo testamento. Rio de Janeiro: Sociedade Bíblica do Brasil, 1966.
BRASIL. Presidência da República. Secretaria Especial de Políticas para as Mulheres. Mapa da Violência. 2015. Disponível em <http://www.mapa da violência.org.br>. Acesso em: 03 out. 2017.

CANCIAN, Natália. Ministério tira identidade de gênero' e 'orientação sexual' da base curricular. Brasília, 2017. Disponível em: <http://www1.folha.uol.com.br/educacao/2017/04/1873366-ministerio-tira-identidade-de-genero-e-orientacao-sexual-da-base-curricular.shtml>. Acesso em: 03 out. 2017.

ELIOT, Lise. Cérebro azul e rosa: o impacto das diferenças de gênero na educação. Porto Alegre: Penso, 2013.

FOUCAULT, Michel. A ordem do discurso. São Paulo: Edição Loyola, 2001.

Arqueologia do saber. Rio de Janeiro: Forense Universitária, 2009.

The history of sexuality: an introduction. New York: Knopf Doubleday, 2012.

HOUAISS, Antônio. Dicionário Houaiss da Língua Portuguesa. Rio de Janeiro: Objetiva, 2001.

INSTITUTO BRASILEIRO DE GEOGRAFIA E ESTATÍSTICA - IBGE. Estatísticas do Cadastro Central de Empresas. 2015. Disponível em: <https://ww2.ibge.gov.br/ home/estatistica/pesquisas/pesquisa_resultados.php?id_pesquisa=9>. Acesso em: 03 out. 2017.

MADALOZZO, R.; MARTINS, S. R.; SHIRATORI, L. Participação no mercado de trabalho e no trabalho doméstico: homens e mulheres têm condições iguais? Estudos Feministas, v. 18, n. 2, p. 547-566, 2010.

ROCHA, Ruth. Romeu e Julieta. Ilustração Mariana Massarani. São Paulo: Salamandra, 2009.

SCHWAB, Gabriele. The Mirror and the Killer-Queen: otherness in literary language. Indianápolis: Indiana University Press, 1996.

VYGOTSKY, Lev Semenovich. Psicologia Pedagógica. 3. ed. São Paulo: Martins Fontes, 2010. 